\title{
Oncology research in Saudi Arabia over a 10-year period
}

\author{
A synopsis
}

\author{
Majed A. Alghamdi, MBBS, FRCPC, Rajab A. Alzahrani, MBBS, FEBORL, Hashem H. Alhashemi, MBBS, FRCPC, \\ Arwa A. Obaid, MBBS, Ali G. Alghamdi, MBBS, Facharzt, Mohammed A. Aldokhi, Medical Student, \\ Amal M. Alghamdi, Medical Student, Abdulaziz A. Alghamdi, Medical Student, Ahmed S. Qanat, Medical Student, \\ Wasil A. Jastaniah, MBBS, FRCPC, Suliman M. Alghamdi, MBBS, FRCPC.
}

\begin{abstract}
الأهداف: تقييم جودة وكمية المنشورات السعودية في علم الأورام على مدار 10

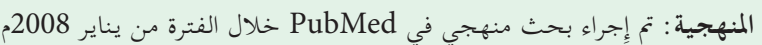

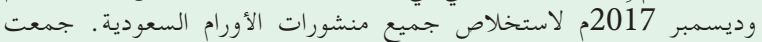

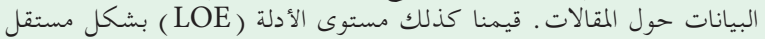

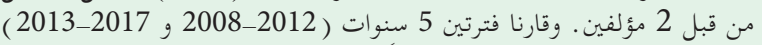

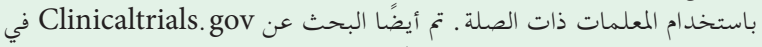
جميع تجارب الأورام المسجلة في المملكة العربية السعودية .

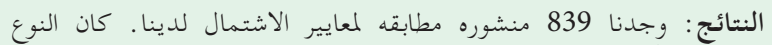

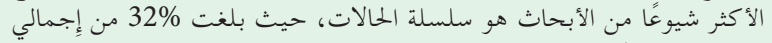

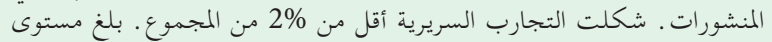

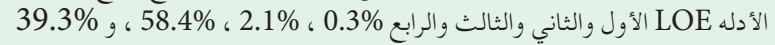

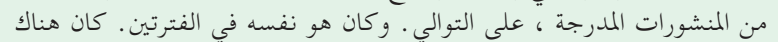

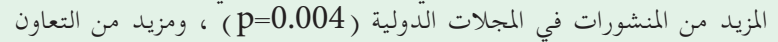

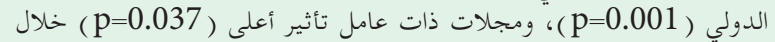

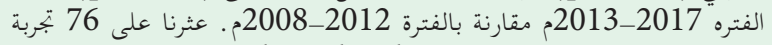
سريرية مسجلة فقط في سجل Clinicaltrials. gov مقارنة

الخلاصة : على الرغم من زيادة عدد المنشورات السعودية في مجال علم الأورام

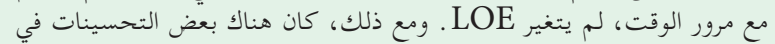

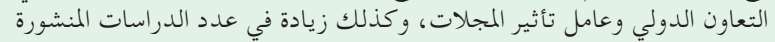

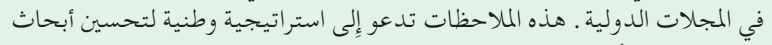

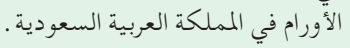

Objectives: To assess the quality and quantity of Saudi publications in oncology over a 10-year period.

Methods: A systematic PubMed search was conducted between January 2008 and December 2017 to retrieve all Saudi oncology publications. Data about the articles was collected. The level of evidence (LOE) was independently assessed by 2 authors. Two 5 -year periods (2008-2012 and 2013-2017) were compared using the relevant parameters. Clinicaltrials.gov was also searched for all oncology trials registered in Saudi Arabia.
Results: A total of 839 publications met our inclusion criteria. The most common type of research was case series, totaling $32 \%$ of all publications. Clinical trials formed less than $2 \%$ of the total. The LOE was I, II, III, and IV in $0.3 \%, 2.1 \%, 58.4 \%$, and $39.3 \%$ of the included publications, respectively. The LOE was the same in the 2 periods. There were more publications in international journals $(p=0.004)$, more international collaborations $(p=0.001)$, and higher journal impact factors $(p=0.037)$ in 2013-2017 than in 2008-2012. Only 76 registered clinical trials were found in the Clinicaltrials.gov registry.

Conclusion: Despite an increase in the number of Saudi publications in the field of oncology over time, the LOE did not change. There were, however, some improvements in the international collaboration and journal impact factor, as well as an increase in the number of studies published in international journals. These observations call for a national strategy to improve oncology research in Saudi Arabia.

Keywords: Saudi, oncology, cancer, level of evidence

Saudi Med J 2020; Vol. 41 (3): 261-266 doi: $10.15537 /$ smj.2020.3.24912

From the Department of Internal Medicine (Alghamdi), from the Department of Surgery (Alzahrani), Faculty of Medicine (Aldokhi, Alghamdi), Al-Baha University, Al-Baha; from the Department of Internal Medicine (Alhashemi), King Abdulaziz Medical City, Ministry of National Guard; from the Department of Oncology (Jastaniah, Alghamdi), Princess Noorah Cancer Center, King Abdulaziz Medical City, Ministry of National Guard; from the Faculty of Medicine (Alghamdi, Qanat), King Abdulaziz University; from King Saud Bin Abdulaziz University for Health Sciences (Alghamdi); from King Abdullah International Medical Research Center (Alghamdi), Jeddah; from the Department of Pediatrics (Jastaniah), Faculty of Medicine, Umm AlQura University, Makkah, Kingdom of Saudi Arabia.

Received 28th August 2019. Accepted 6th January 2020.

Address correspondence and reprint request to: Dr. Majed Alghamdi, Department of Internal Medicine, Faculty of Medicine, Al-Baha University, Al-Baha, Kingdom of Saudi Arabia. E-mail: malghamdi1984@gmail.com ORCID: https://orcid.org/0000-0003-0779-079X 
$\mathrm{L}$ ike many branches of medicine, oncology is a dynamic field experiencing rapid changes in practice. Many international institutions established clinical practice guidelines for treating most types of cancers..$^{1-3}$ These guidelines are reviewed and updated periodically by a panel of experts in the field with a focus on the highest level of evidence (LOE). The highest LOE, level I, is achieved through phase III randomized clinical trials. Although there are obstacles in conducting such trials, many oncology research groups around the world have succeeded in designing, recruiting participants, and completing well performed clinical trials that have had a profound influence on global cancer treatment over the years.

In Saudi Arabia, national cancer treatment guidelines are based on data derived from different populations. 4,5 As cancers can vary in natural history, epidemiology, and clinical outcomes between countries, it is important to study each cancer type, especially the common ones, in the local population. ${ }^{6-9}$ Clinical research will greatly help Saudi physicians to understand these cancers and assess the outcomes for local patients, who are usually treated according to the existing evidence from other countries.

Given the improving research facilities in Saudi Arabia and the increasing number of practicing oncologists, this was an appropriate time to study the trends in the quantity and quality of oncology research publications from Saudi Arabia over a 10-year period

Methods. PubMed, Medline, and Embase were searched for all English-language articles from Saudi Arabia published between January 2008 and December 2017. This study was considered a minimal risk and therefore did not require the full approval of the research ethics board. Each database was searched using the key words "cancer," "oncology," "tumor" or "tumour," and "Saudi Arabia". Additionally, another search was conducted by using the names of all relevant Saudi institutions, including hospitals, medical cities, cancer centers, and universities. The abstracts of these studies were independently screened by the 2 authors (oncologists) of this paper and only those that reported on the Saudi population or had at least one author who was affiliated with a Saudi institution were included. Duplicate publications, letter to editors, and non-

Disclosure. Authors have no conflict of interests, and the work was not supported or funded by any drug company. oncology-related publications were excluded. Preclinical and laboratory-based papers that did not incorporate clinical correlations were also excluded.

After a thorough review of the relevant papers, the following information was collected: the article name and year of publication, the names of the first and senior authors and their affiliations and specialties, collaboration with international institutions, the type of research, the journal name and impact factor at the time of publication, and the number of citations for the article as of March 31, 2018. The 2- or 5-year impact factor was extracted from the journal's official website or by using Google Scholar. The number of times the paper had been cited was obtained using Google Scholar.

An LOE was independently assigned to each article according to the 2011 Oxford Center of Evidence-Based Medicine (OCEBM) Levels of Evidence ${ }^{10}$ by each of the 2 authors. All discrepancies were resolved through discussion between the authors or by consulting an expert epidemiologist.

Two 5-year periods (2008-2012 and 2013-2017) were compared and trends in the number and quality of the publications were examined. The measures used to determine quality included the type of research (namely, clinical trial, observational), the presence of international collaborations, the impact factor of the journal $(\geq 1$ or $<1)$ at the time of publication, whether it was an international or a Saudi journal, and the LOE (I/ II or III/IV). Research leading specialist was considered an oncologist when the study lead author was a medical oncologist, radiation oncologist, pediatric oncologist, or hemato-oncologist. All other studies, including those led by oncology surgeons, neurosurgeons, head and neck surgeons, and others, were considered nononcologist-led research. The lead author was defined as the first author. In cases where the first author listed was not a consultant (for example, a student), the senior author (last author) was considered the lead author.

The Clinicaltrials.gov site was also searched to review the number and the fate of all registered clinical trials up to March 31, 2018, that were based in or included the participation of at least one Saudi center.

Analyses were performed using the SPSS software (version 22, IBM Corporation, NY, USA). We used the Pearson Chi-Square test with 2-sided $p$-values to compare the different quality measures between the 2 time periods; $p<0.05$ was chosen as a level of statistical significance.

Results. After screening the initial 3725 abstracts, 839 abstracts that met our inclusion criteria were included. As seen in Figure 1, the number of publications 
increased over the 10-year period. Only 19 studies were conducted in a prospective manner. The research studies included 241 case reports, 265 case series, 4 cohort studies, 111 cross-sectional studies that included surveys and epidemiological studies, 37 case-control studies, 125 narrative review articles, 8 systematic reviews and/or meta-analysis, 26 guidelines, 14 clinical trials ( 2 phase I, nine phase II, and 3 phase III), and 8 studies that could not be classified (Figure 2).

Among the 9 phase II studies, only 2 were randomized trials. International collaborations were found in 182 studies $(21.7 \%)$. The overall LOE was I in $2(0.3 \%)$ studies, II in $14(2.1 \%)$ studies, III in 398 (58.4) studies, and IV in 268 studies (39.3\%). Level of evidence could not be applied in 157 studies. The median number of citations was 4 . The median

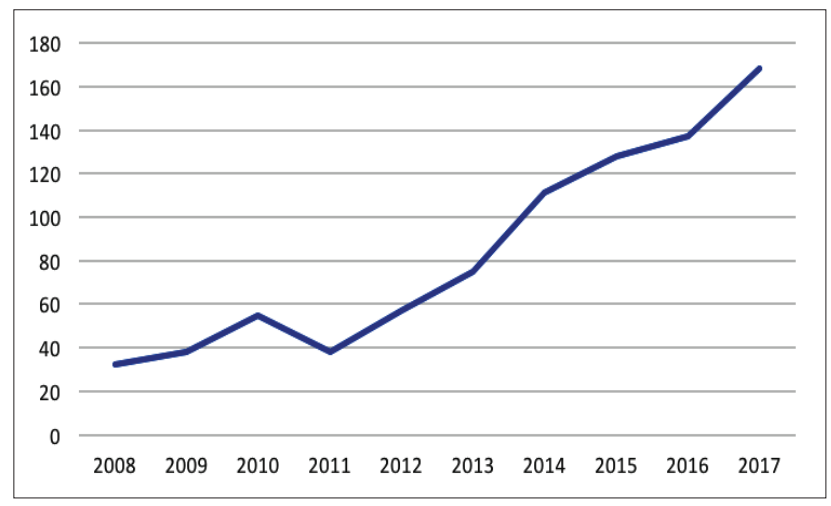

Figure 1 - Overall trend for Saudi publications in oncology, 2008-2017. journal impact factor was 1.5 . Using 1 as a cut-off point, a journal impact factor of $\geq 1$ was found in 503 publications $(66.4 \%)$, while 255 publications (33.6\%) were in journals with an impact factor of $<1$ and 81 publications were in journals with an unknown impact factor. There were 256 oncologist-led studies (30.5\%) and 583 non-oncologist-led studies (69.5\%). A majority of the studies $(15.1 \%)$ were published by pathologists, as summarized in Table 1.

Table 1 - Saudi publications in oncology by specialty, 2008-2017.

\begin{tabular}{lrr}
\hline Specialty & n & \multicolumn{1}{c}{$(\%)$} \\
\hline Medical oncology & 84 & $(10.0)$ \\
Radiation oncology & 65 & $(7.8)$ \\
Adult hemato-oncology & 66 & $(7.9)$ \\
Pediatric hemato-oncology & 35 & $(4.2)$ \\
Surgical oncology & 75 & $(8.9)$ \\
Head and Neck & 36 & $(4.3)$ \\
Neurosurgery & 21 & $(2.5)$ \\
Urology & 27 & $(3.2)$ \\
Gynecology & 32 & $(3.8)$ \\
Orthopedics & 5 & $(0.6)$ \\
Plastic & 4 & $(0.5)$ \\
Medicine & 67 & $(8.0)$ \\
Pediatrics & 7 & $(0.8)$ \\
Dermatology & 9 & $(1.1)$ \\
Psychiatry & 4 & $(0.5)$ \\
Epidemiology & 31 & $(3.7)$ \\
Pathology & 127 & $(15.1)$ \\
Radiology & 28 & $(3.3)$ \\
Palliative medicine & 11 & $(1.3)$ \\
Others & 105 & $(12.5)$ \\
\hline
\end{tabular}

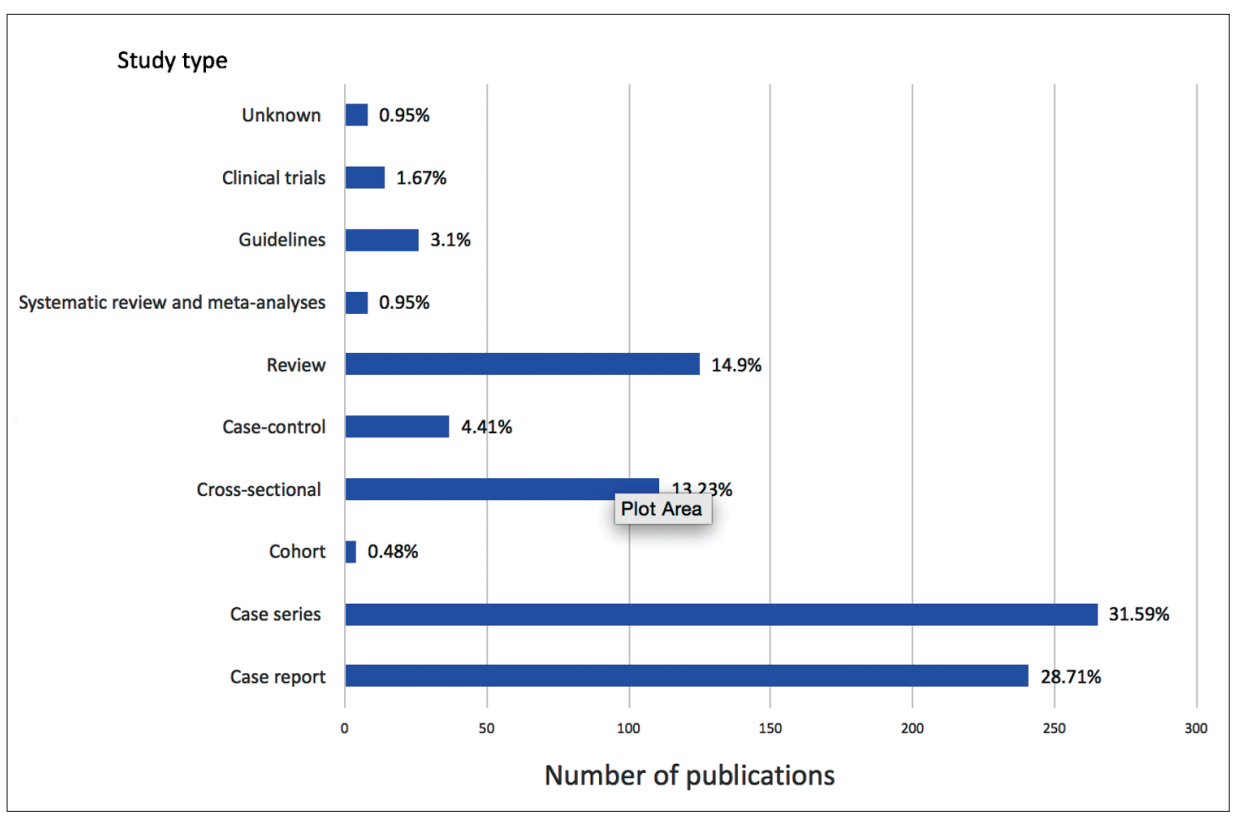

Figure 2 - Types of Saudi oncology studies, 2008-2017. 
With regard to the institutional affiliation of the lead author, the most frequently occurring institutions were the King Faisal Specialist Hospital and Research Centers in Riyadh and Jeddah with 266 publications (31.7\%), followed by the King Saud University with 142 publications (16.9\%) and the Ministry of National Guard hospitals including the King Saud bin Abdulaziz University with 69 publications (8.2\%). There were 106 studies published in Saudi journals (12.6\%), while 732 studies $(87.3 \%)$ were published in international journals (the publication status of one study was unknown).

A comparison was made between papers published during the periods 2008-2012 and 2013-2017. The number of publications in international journals compared to Saudi journals increased in the second period compared to the first $(p=0.004)$. Similarly, international collaborations $(p=0.001)$ and the impact factor $(\geq 1$ or $<1)$ of the journals improved in the second period $(p=0.037)$. Comparisons between clinical trials and other studies $(p=0.681)$, LOE of I/II and LOE of III/IV $(p=0.279)$, and oncologist-led studies and non-oncologist-led studies $(p=0.594)$ did not show statistically significant changes between the 2 periods. Table 2 summarizes these findings.

A search of Clinicaltrials.gov found a total of 76 trials up to March 31, 2018. Of these, 29 trials (38.2\%) were launched and based in a Saudi center and 47 (61.8\%) were based outside of the country. Of the trials based in Saudi Arabia, only 3 involved collaboration with at least one other national center and 3 involved participation of one or more international centers. Of the 29 Saudi studies, 6 were terminated due to poor accrual. Only one terminated study involved collaboration with another national center; no national or international collaboration was found in the other terminated studies. There were no terminations in the non-Saudi-based trials. Figure 3 summarizes these findings.

Discussion. High quality research is essential to advance medical practice. Given the inherent differences in cancer epidemiology and outcomes between countries, it is imperative that cancers are studied in local populations. ${ }^{6-9}$ In Saudi Arabia, there has been an increase in the number of cancer centers and practicing cancer specialists over the past 10 years. However, there are no reported data on the status of oncology research in Saudi Arabia or on research quality and trends over time. In this study, we found the overall trend to be upward in terms of the number of publications. However, the LOE did not change between the two 5-year periods, (2008-2012 and 2013-2017) and there were only 14 clinical trials. The quality of research we found in this study is mostly better than or at least similar to what was found in other studies concerning different specialties in Saudi Arabia. For example, in a similar study on Saudi neurosurgery publications, the LOE was IV in $91 \%$ of 377 publications over a longer time frame compared to $39.3 \%$ in our study. ${ }^{11}$ International

Table 2 - Comparison between the two 5-year periods (2008-2012 and 2013-2017).

\begin{tabular}{|c|c|c|c|}
\hline Compared elements & $\begin{array}{c}2008-2012 \\
\mathrm{n}(\%)\end{array}$ & $\begin{array}{c}2013-2017 \\
(\%)\end{array}$ & $P$-value ${ }^{\ddagger}$ \\
\hline $\begin{array}{l}\text { Journals } \\
\text { International } \\
\text { Saudi } \\
\text { Unknown value }\end{array}$ & $\begin{array}{r}180(81.4) \\
40(18.1) \\
1 \quad(0.5)\end{array}$ & $\begin{array}{r}552(89.3) \\
66(10.7)\end{array}$ & 0.004 \\
\hline $\begin{array}{l}\text { International collaborations } \\
\text { (journals with international collaboration/ } \\
\text { total) }\end{array}$ & $1 / 220 \quad(0.5)$ & $187 / 619(30.2)$ & 0.001 \\
\hline $\begin{array}{l}\text { Impact factor } \\
\quad<1 \\
\quad \geq 1 \\
\quad \text { Unknown value }\end{array}$ & $\begin{array}{r}79(35.9) \\
127(57.7) \\
14(6.4)\end{array}$ & $\begin{array}{r}176(28.4) \\
376(60.8) \\
67(10.8)\end{array}$ & 0.037 \\
\hline $\begin{array}{l}\text { Type of studies } \\
\text { Clinical trial } \\
\text { Others }\end{array}$ & $\begin{array}{r}3(1.4) \\
217(98.6)\end{array}$ & $\begin{array}{rr}11 & (1.8) \\
608 & (98.2)\end{array}$ & 0.681 \\
\hline $\begin{array}{l}\text { Levels of evidence (I/II vs. III/IV) } \\
\text { I/II } \\
\text { III/IV } \\
\text { Not applicable }{ }^{\dagger}\end{array}$ & $\begin{array}{r}3(1.6) \\
183(98.4) \\
34\end{array}$ & $\begin{array}{r}13(2.6) \\
484(97.4) \\
122\end{array}$ & 0.279 \\
\hline $\begin{array}{l}\text { Research leading specialist } \\
\text { Oncologist } \\
\text { Others }\end{array}$ & $\begin{array}{r}64(29.1) \\
156(70.9)\end{array}$ & $\begin{array}{l}192(31.0) \\
427(69.0)\end{array}$ & 0.594 \\
\hline
\end{tabular}




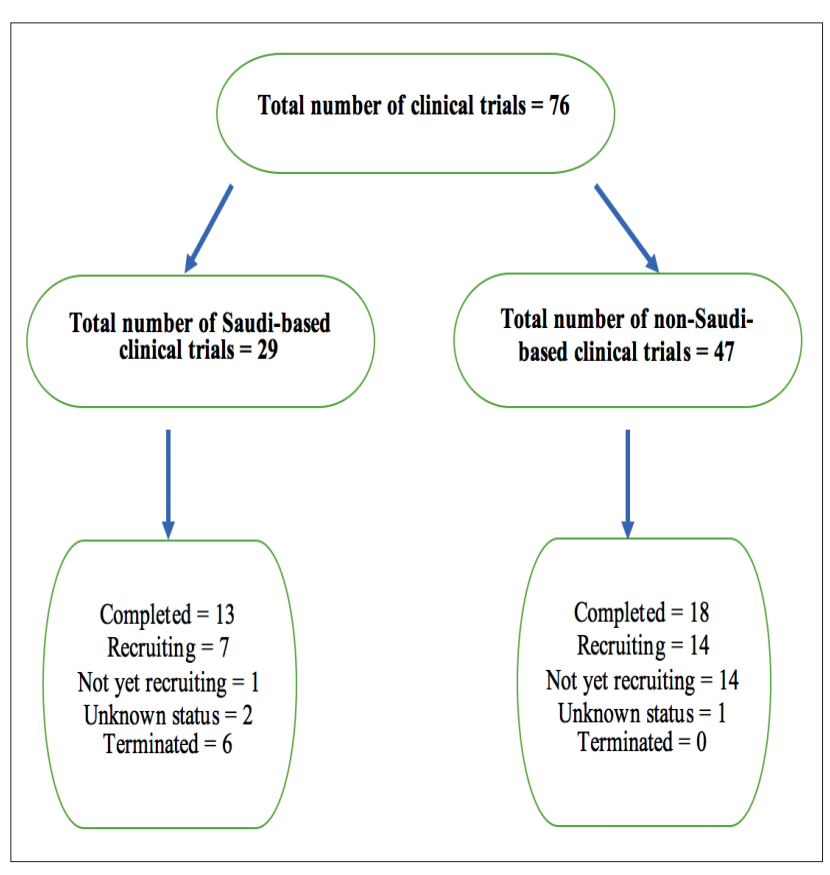

Figure 2 - Status of oncology clinical trials in Saudi Arabia up to March 31, 2018.

collaborations made up $10.9 \%$ of the total publications compared to $21.7 \%$ in our study, and Saudi journals accounted for $26 \%$ of the publications, compared to $12.6 \%$ in our study. The median number of citations in that study $(\mathrm{n}=11)$ was higher than that observed in our study $(n=4)$, which may be a reflection of the longer time frame. The journal impact factor, using 1 as a cut-off point, was similar in both studies: $64.5 \% \geq 1$ and $35.5 \%<1$ in the neurosurgery study, compared to $66.4 \% \geq 1$ and $33.6 \%<1$ in our study.

Two other studies examined the LOE in the Saudi literature for orthopedic (86\%) and plastic surgery (91\%) and found that most publications were associated with LOE IV. ${ }^{12,13}$ Consistent with our findings, the orthopedic study found no difference in the LOE over 2 decades. Two more studies that reported on Saudi publications for abdominal surgery $(50.5 \%)$ and clinical epilepsy $(53.3 \%)$ found that the LOE was mostly III, which is close to our value of $58.4 \% .^{14,15}$ We could not find any international data on oncology research for comparison.

It is also important to note that about $75.2 \%$ of all studies we found were case reports, case series and review articles which have a limited contribution to the literature. This implies that there is a lack of knowledge about cancer epidemiology and cancer patient outcomes in Saudi Arabia. Interestingly, most of the included publications in our study were considered novel with no preceding similar studies from Saudi Arabia. The unique aspect of this study lies in providing novel and detailed data about Saudi publications in a specialized field. We looked at the number of publications by institutions and specialties. Not surprisingly, most of the publications came from the King Faisal Specialist Hospital and Research Centers in Riyadh and Jeddah $(31.7 \%)$. This is probably due to the advanced and pioneering oncology services and research facilities in these hospitals compared to others in Saudi Arabia. Though we excluded preclinical and laboratory-based data, Saudi pathologists published a majority of the studies in clinical oncology in Saudi Arabia over the examined period; most of these publications involved at least one co-author from a clinical specialty. This is a good example of collaboration between different specialists in conducting research, which may have resulted in a higher number of publications by pathologists as compared to other specialists.

To provide an insight into oncology clinical trials in Saudi Arabia, we reviewed all clinical trials conducted in Saudi Arabia that were registered on Clinicaltrials.gov up to March 31, 2018. As indicated in Figure 3, a total of 76 trials were found; 29 of those were initiated and based in Saudi Arabia. None of the trials that were based out of the country was terminated, while 6 of the Saudi-based ones were terminated due to poor accrual. Only 3 Saudi-based clinical trials involved a collaboration with at least one other national center and 3 other trials involved participation of one or more international centers. Among the Saudi-based studies that were terminated, only one (1/6) involved collaboration with another national center. This indicates that collaboration with other centers may be necessary for complete accrual for oncology trials in Saudi Arabia. The relatively low number of clinical trials in Saudi Arabia must be interpreted with caution, as there may be some in-house studies that were not registered on Clinicaltrials.gov. It is important to differentiate between the 14 published clinical trials that we found for the period 2008-2017 and the 76 registered trials on Clinicaltrials.gov that included all clinical trials up to March 31, 2018.

Cancer centers in Saudi Arabia apply a high and the most recent standard of care for cancer patients. Although some centers have a reasonable in-place research framework, there are existing challenges in conducting research, especially clinical trials, in Saudi Arabia. ${ }^{16,17}$ For clinicians working in high-volume cancer centers, there is usually limited time for research, especially for time-consuming and labor-intensive clinical trials. Furthermore, the drive to conduct research 
is limited, to a large extent, to academic institutions. ${ }^{18}$ Research funding and cultural factors are other major obstacles. Speaking to these issues, we are conducting a nationwide cross-sectional study examining the factors that limit research productivity from the perspective of practicing Saudi oncologists. To overcome some of the challenges in conducting clinical trials, an increase in national collaboration is required. Successful examples of such collaborations are evident in North American and European institutions. ${ }^{19-21}$

This paper is an observational study of Saudi publications in the field of oncology; it may also serve as a metric to measure improvements in the quality of Saudi oncology research in the future. The limitations of this study include the fact that we may have missed some studies due to misspellings of the institutional names, some studies not being registered on clinicaltrials.gov or indexed in PubMed, or studies being published in languages other than English. The number of citations for each study was checked using Google Scholar, which has its own limitations, and was concluded by March 31, 2018, potentially excluding citations for studies published after that date. Similarly, the historical journal impact factor at the time of publication was missing for some of the journals, so Google Scholar was used as an alternative. Finally, grouping the LOE into 2 groups (I/II and III/IV) is probably not ideal; we chose to do so based on the strength of the LOE and to allow for a simplified comparison of the 2 groups with a respectable number of studies.

In conclusion, despite the increasing volume of Saudi publications in the field of oncology over time, the quality of research did not change. However, there were some improvements in the amount of international collaboration and journal impact factor, as well as an increase in the number of studies published in international journals, though only a few clinical trials were found. These observations call for a national strategy to improve oncology research in Saudi Arabia. One approach is to establish multidisciplinary and collaborative national research groups concerning each specific cancer site.

\section{References}

1. Cancer Care Ontario. Ontario Cancer Management Guidelines. [Accessed 2019 November 25]. Available from: https://www. cancercareontario.ca/en/guidelines-advice

2. British Columbia Cancer Management Guidelines. [Accessed 2019 November 25]. Available from: http://www.bccancer. bc.ca/health-professionals/clinical-resources/cancermanagement-guidelines.

3. National Comprehensive Cancer Network. [Update: Accessed 2019 November 25]. Available from: https://www.nccn.org
4. Jazieh AR, Al Kattan K, Bamousa A, Al Olayan A, Abdelwarith A, Ansari J, et al. Saudi lung cancer management guidelines 2017. Ann Thorac Med 2017; 12: 221-246.

5. Alghamdi A, Alkhateeb S, Alghamdi K, Bazarbashi S, Murshid E, Alotaibi M, et al. Saudi Oncology Society and Saudi Urology Association combined clinical management guidelines for renal cell carcinoma. Urol Ann 2016; 8: 136-140.

6. Choi E, Lee S, Nhung BC, Suh M, Park B, Jun JK, et al. Cancer mortality-to-incidence ratio as an indicator of cancer management outcomes in Organization for Economic Cooperation and Development countries. Epidemiol Health 2017; 39: e2017006.

7. Fitzmaurice C, Akinyemiju TF, Al Lami FH, Alam T, AlizadehNavaei R, Allen C, et al. Global, Regional, and National Cancer incidence, mortality, years of life lost, years lived with disability, and disability-adjusted life-years for 29 Cancer Groups, 1990 to 2016: A systematic analysis for the global burden of disease study. JAMA Oncol 2018; 4: 1553-1568.

8. Fitzmaurice C, Allen C, Barber RM, Barregard L, Bhutta $\mathrm{ZA}$, Brenner $\mathrm{H}$, et al. Global, regional, and national cancer incidence, mortality, years of life lost, years lived with disability, and disability-adjusted life-years for 32 cancer groups, 1990 to 2015: A systematic analysis for the global burden of disease study. JAMA Oncol 2017; 3: 524-548.

9. Althubiti MA, Nour Eldein MM. Trends in the incidence and mortality of cancer in Saudi Arabia. Saudi Med J 2018; 39: 1259-1262.

10. Centre for Evidence-Based Medicine. OCEBM Levels of Evidence. [Update 2016 May 1; Accessed 2019 November 25]. Available from: https://www.cebm.net/2016/05/ocebm-levelsof-evidencel

11. Jamjoom BA, Jamjoom AA, Jamjoom AB. Level of evidence of clinical neurosurgery research in Saudi Arabia. Neurosciences (Riyadh) 2014; 19: 334-337.

12. Makhdom AM, Alqahtani SM, Alsheikh KA, Samargandi OA, Saran N. Level of evidence of clinical orthopedic surgery research in Saudi Arabia. Saudi Med J 2013; 34: 395-400.

13. Samargandi OA, Makhdom AM, Kaur M, Awan BA, Thoma A. Level of evidence of plastic surgery clinical research in Saudi Arabia. Saudi Med J 2013; 34: 1197-118.

14. Maghrabi Y, Baeesa M, Kattan J, Altaf A, Baeesa SS. Level of evidence of abdominal surgery clinical research in Saudi Arabia. Saudi Med J 2017; 38: 788-793.

15. Baeesa SS, Maghrabi YE, Baeesa MS, Jan FM, Jan MM. Publications pattern of clinical epilepsy research in Saudi Arabia. Neurosciences (Riyadh) 2017; 22: 255-260.

16. Nair SC, Ibrahim H, Celentano DD. Clinical trials in the Middle East and North Africa (MENA) Region: grandstanding or grandeur? Contemp Clin Trials 2013; 36: 704-710.

17. Mbuagbaw L, Thabane L, Ongolo-Zogo P, Lang T. The challenges and opportunities of conducting a clinical trial in a low resource setting: the case of the Cameroon mobile phone SMS (CAMPS) trial, an investigator initiated trial. Trials 2011; 12: 145 .

18. Ali S, Alghamdi MA, Alzhrani JA, De Vol EB. Magnitude and characteristics of clinical trials in the Kingdom of Saudi Arabia: A cross-sectional analysis. Contemp Clin Trials Commun 2017; 7: 126-129.

19. NRG Oncology. [Update: Accessed 2019 November 25]. Available from: https://www.nrgoncology.org/

20. The Children's Oncology Group. [Accessed 2019 November 25]. Available from: https://www.childrensoncologygroup.org/

21. European Organisation for Research and Treatment of Cancer. [Accessed 2019 November 25]. Available from: https://www. eortc.org 